\title{
Assessment of sleep characteristics of pediatric population with nocturnal enuresis: A tertiary hospital questionnaire- based study
}

\author{
Selçuk Sarıkaya ${ }^{1}$, Fatma Gökçem Yıldız ${ }^{2}$, Nejdet Karşıyakalı ${ }^{3}$, Erman Damar ${ }^{4}$, Çağrı Şenocak ${ }^{5}$, Ömer Faruk \\ Bozkurt ${ }^{5}$ \\ (1) University of Health Sciences, Gulhane Training and Research Hospital, Department of Urology, Ankara, Turkey \\ (2) Hacettepe University, Faculty of Medicine, Department of Neurology, Ankara, Turkey \\ (3) Hakkari Cukurca State Hospital, Department of Urology, Hakkari, Turkey \\ (4) Diyarbakir Bismil State Hospital, Department of Urology, Diyarbakir, Turkey \\ (5) University of Health Sciences, KeciorenTraining and Research, Department of Urology, Ankara, Turkey
}

Date submitted:

Feb 27, 2019

Date accepted:

Apr 19, 2019

Online publication date:

September 15, 2019

\section{Corresponding Author: \\ Nejdet Karşıyakalı \\ Hakkari Cukurca State Hospital, \\ Department of Urology, Hakkari, \\ Turkey \\ nkarsiyakali@hotmail.com}

Keywords: Enuresis, MOS sleep measure, Nocturnal enuresis, Sleep, Sleep quality, Survey.

\begin{abstract}
Aims:Nocturnal enuresis (NE) is a frequent pathological entity and it is known that children with NE have deeper sleep pattern and get diffuculty to wake up. In this prospective controlled study we aimed to determine which dimensions of sleeping quality were getting worsen in children with enuresis by using Medical Outcomes of Study Sleep Scale (MOS-SS).
\end{abstract}

Methods:Between 2014 July to 2017 July 53 children with monosymptomatic NE and 27 controls were included in the study. After excluding any other urological and neurological disaseases, patients parents' were requested to fill out the MOS-SS questionnaire form. According to questionnaire outcomes, groups were compared for the subdimensions of sleep quality.

Results:There were no significant differences between the groups in terms of age, gender and other demographical features ( $p>0.05$ ). According to MOS-SS questionnaire results, there was no difference between groups in terms of snoring, shortness of sleep, sleep hours per night and daytime somnolence scores ( $p>0.05$, for all subdomains). In contrast, sleep disturbance scores were significantly higher in patients with enuresis compared to the control group while adequacy of sleep scores were statistically higher in control group $(p<0.05)$.

Conclusions:Assessment of sleep quality is very important for defining the underlying cause of NE. Children with NE are affected with sleep disturbance and do not have enough sleep adequacy according to MOS-SS questionnaire. Neurophysiologic studies would be needed for confirming the sleep disorders in addition to MOS-SS questionnaire.

\section{Introduction}

Sleep is an important factor for well-being, good health status, life quality in general population, also it is very important for well-growthing in childhood. Sleep problems may affect mental and physical condition of patients, and also with poor social interaction (1). Nocturnal enuresis (NE) is a frequent pathological entity in pediatric population and can cause sleep problems (2). According to the International Children's Continence Society (ICCS), enuresis is both a symptom and a condition of intermittent incontinence that occurs during periods of sleep. Enuresis is not more synonymous with nocturnal incontinence in line with the update report of the standardization committee of the ICCS (3). Primary monosymptomatic enuresis is used for the children who have not any other lower urinary tract (LUT) symptoms and bladder dysfunction, also have not a previous dry episode for at least 6 months (4). Terminology of NE only can be used for pediatric patients over 5 years old (4). It is associated with nocturnal hyperactivity of bladder, having a deep sleep, excessive nocturnal urine production and failure to awaken in response to bladder sensations during the night (5). Treatment options of NE include behavioral therapy, alarm therapy and desmopres- sin. There is not any consensus about which therapy should be chosen in which patient yet. Also most of these children are healing without taking any treatment (4).

Enuretic children parents' commonly complain with a severe deepness of children's sleep and difficulty to wake up the child (6). Due to this condition it also affects the quality of life (QoL), but some opposite informations exist in the literature on QoL $(4,7)$. The overall prevelance ranges between $1.6 \%$ and $15 \%$, but it declines with increasing age $(8,9)$. As the children get older, this condition becomes a bigger and distressing condition for both children and parents (10). Studies assessed the QoL for mothers of children with NE and it is indicated that they are negatively affected from this condition (11). The parents are found to have more anxiety due to this problem and their marital relations were also found to be affected (12). There are some risk factors found to be associated with NE such as age group, parental education level and family history of enuresis (13). The relation between enuresis and sleep disorders were assessed in many previous studies $(2,14)$. It was reported that there was a close relation between these two entities and also it is obvious that there is bidirectional interaction. According to 
the studies reported in the literature, the children who have NE have daytime sleepiness and disturbed daily behaviours (15). Questionnaires and scales were used in order to assess this relation (4). Medical Outcomes of Study-Sleep Scale (MOS-SS) is a 12-item self-report questionnaire form and used for assessing 6 dimensions of sleep quality and quantity in patients and in the general population for over the past 4 weeks (16).

In this study, we aimed to improve the treatment success of neurological rehabilitation strategies that are more effective, targeted and empirically supported in patients with NE and to reveal neglected sleep problems in patients by using MOS-SS. According to our knowledge, it is the first study assessing sleep problems among children with NE using this sleep scale.

\section{Methods}

The study was designed as a prospective controlled study. Between July 2014 and July 2017, Fifty-three patients (36 boys and 17 girls) with the diagnosis of monosymptomatic NE and 27 controls (17 boys and 10 girls) were included in the study. Ethical committee approval for the study was obtained from the Kecioren Research and Training Hospital Local Ethics Committee. All patients were evaluated with urine sample, routine biochemical analysis of blood test, pelvic ultrasound and post-micturitional residual urine volume to exclude any other urologic and neurologic pathologies. In addition, a 7-night and 48 hours daytime bladder diary was obtained to evaluate enuresis and LUT dysfunction. Study populations' parents were requested to fill out the MOS-SS questionnaire form. Age, gender, family history, educational status, concomitant diseases and sleep factors were assessed in detail. As mentioned above the MOS-SS is a self-report questionnaire form and used for assessing 6 dimensions of sleep quality and quantity. It examines the subjectives by using a Likert-type Scale. MOSS-SS includes a few subscales; a sleep quantity subscale, a sleep problem index and five subscales. The five sleep quality subscales includes sleep disturbance, snoring, awaken short of breath or with headache, sleep adequacy, and daytime somnolence. With the exception of sleep quantity, scores of each index range from 0 to 100 , higher scores indicate higher levels of the concept being measured. Quantity of sleep is scored as the average hours slept per night (16). For this study, the data were collected during a baseline assessment for a longitudinal study of self-reported health outcomes in patients with enuresis nocturna. Patients who did not respond to the questionnaire form, who left an incomplete answer on the form, who were diagnosed as non-monosymptomatic NE (e.g., day time incontinence, urgency, hesitancy, LUT pain etc.) and who had comorbidities that would affect their sleep quality (e.g., obstructive sleep apnea syndrome and tonsil hypertrophy) were excluded from the study.

The data of study was evaluated with SPSS 22 Package Program. As a result of normality test, while differences between the groups were examined, Mann Whitney $U$ Test was used for the non-normally distributed variables in dual groups. Chisquare test was used for assessing the dependence between variables. A $p$ value of $<0.05$ was considered statistically significant.

\section{Results}

A total of 53 patients with monosymptomatic NE were included in the study (mean age: $9.05 \pm 1.7$ ). Seventeen of the patients were girls and 36 were boys. The total control group was 27 participants; 10 were girls and 17 were boys (mean age: $8.6 \pm 2.4$ ). There was no statistically significant difference between groups in terms of age and gender ( $p>0.05)$. Educational success and family history were assessed for the patient group. There was no statistically difference reported for the educational success of the patient group. While assessing the family history about enuresis, there was 7 paternal positivity, 6 maternal positivity and 5 both maternal and paternal positivity in patient group. Concomittant diseases were also collected. Three patients had asthma, 1 patient had anemia and 1 patient had developmental problem.

According to MOS-SS questionnaire results there was no difference between control group and patient group in terms of snoring scores, shortness of sleep scores, sleep hours per night and daytime somnolence scores ( $p>0.05$, for all subdomains). In contrast, sleep disturbance scores were significantly higher in patients with enuresis compared to the control group while adequacy of sleep scores were statistically higher in control group $(p<0.05)($ Table 1$)$.

\section{Discussion}

Enuresis nocturna is a frequent and disstressing pathologic entity among children and it can be a serious problem for children and their parents. Several treatment methods are used such as educational and behavioral therapy, desmopressin, enuretic alarm devices. Different success rates were reported in the literature regarding these treatment modalities. Also overtreatment is a concern, because of spontaneously resolving of enuresis by the time. Fera et al. reported similar success rates for desmopressin and behavioral treatment modalities (17). Withdrawal of desmopressin still remains controversial. Chua et al. indicated that structured withdrawal of desmopressin would be better for avoiding relapses (18). Alarm device is an important treatment option with its higher success and lower recurrence rates but the compliance of families were founded

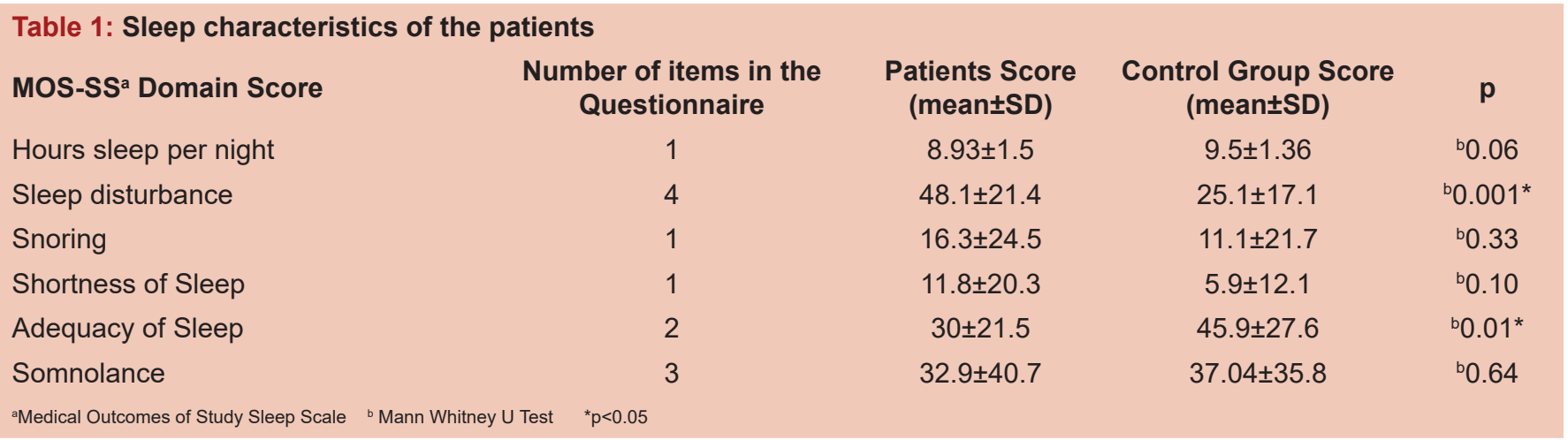


unfortunately lower than expected in studies (19). Ma et al. assessed the importance of behavioral interventions and they were found that behavioral changes affected the therapeutic responses (20). Arena et al. indicated that nocturnal enuresis is highly associatied with bladder and voiding dysfunctions, also constipation. They were reported that multimodal approach would positively affect the treatment outcomes positively (21). Nocturnal enuresis affects quality of life for both children and their parents negatively (10-12).

Several studies have been conducted in order to assess the relation between sleep quality and enuresis $(2,4)$. Psychological state and sleep quality are important issues in enuretic children. Ucer at al. declared that according to their study, children with monosymptomatic NE had not depression but they were unhappy because of their disease (4). Dhondt et al. found higher sleep fragmentation and high periodic limb movements in children with enuresis (22). Esposito et al. used Sleep Disturbances Scale for Children (SDSC) and they were found that nocturnal enuresis would be considered as a risk factor for sleep disorders. Sleep disorders were indicated as one of the important comorbidities of enuresis (8). Our study also indicates the significant difference between patients and control group, in terms of sleep disturbance and sleep adequacy. Sleep disturbance scores were higher in patient group, meaning of this result is that patients have trouble falling asleep, awaken during sleep and have trouble falling asleep again. According to sleep adequacy scores control group have declare that they get enough sleep to feel rested upon waking in the morning and get enough amount of sleep they needed. This outcome could be very important while planning the treatment of enuresis. At this point, evaluating sleep disorders while assessing nocturnal enuresis could be an important situation for providing a successful treatment. Based on the MOS-SS scores maybe clinicians can decide which treatment modality is suitable for patient, and giving more intensive treatment approach for patients who have higher MOSS-SS scores could be an option. Also clinicians can avoid giving overtreatment to children. Kushnir et al. assessed the use of night diapers in children with enuresis. They found that the group that did not use night diapers had impaired sleep patterns and the group that used night diapers had similar sleep quality with healthy children (23). NE is frequently seen in a familial pattern, higher prevalence rates are found in individuals of the family. Studies also revealed genetic factors in enuresis pathogenesis. Oguz et al. (24) showed relation between the age of spontaneous resolution of nocturnal enuresis and familial factors (24). As well as in our study, there were also paternal and maternal positivities. Different study designs used for assessing sleep disturbances by using questionnaires, actigraphies, polysomnography results. However, Soster et al. used a different method, they used cyclic alternating pattern (CAP) in their studies for analyzing sleep microstructure and they found impaired sleep arousal threshold and sleep fragmentation (25). It is very important to reveal sleep problems in patients with NE. Treatment outcomes can be improved according to resolution of associations between NE and sleep disorders.

Although our study has a prospective controlled structure, it has some limitations. First of all our patient population were not big enough. Secondly, we did not divide patients to groups according to treatment modalities that they already had. And finally, we did not offer any treatment modalities how these sleep disorders could be treat according to the MOS-SS questionnaire in children with nocturnal enuresis. Despite these limitations, these subdomains of sleep disorder that we had showed in the present study may be a source for future research for neurophysiologists and practitioners of sleep medicine.

\section{Conclusions}

Assessment of sleep quality is very important for defining the underlying cause of nocturnal enuresis. Patients with nocturnal enuresis are affected with sleep disturbance and do not have enough sleep adequacy according to MOS-SS questionnaire. As it is clearly stated in our study, sleep disorders must be evaluated and treated for providing a successful treatment for nocturnal enuresis. Also neurophysiologic studies would be needed for confirming the sleep disorders in addition to questionnaires and patients could be evaluated if there is any difference on sleep problems according to treatment modalities. More studies with larger patient and control groups are necessary in order to show the bidirectional interaction between sleep quality and nocturnal enuresis.

\section{Acknowledgements}

\section{Authors Contributions}

S.S: Protocol/project development, Manuscript editing, Critical Review

\section{F.G.Y: Protocol/project development}

\section{N.K: Data analysis, Manuscript writing}

E.D: Data analysis, Statistical Analysis

\section{C.S: Data collection or management, Manuscript writing}

O.F.B: Data collection or management, Manuscript writing

Funding: No grants or funding was provided for this study.

Conflict of Interest: The authors declared they do not have anything to disclose regarding conflict of interest with respect to this manuscript.

Ethics: All procedures performed in studies involving human participants were in accordance with the ethical standards of the institutional and/or national research committee and with the 1964 Helsinki declaration and its later amendments or comparable ethical standards.

Informed consent: Informed consent was obtained from all individual participants parents' included in the study.

\section{References}

1. Wallander MA, Johansson S, Ruigomez A, Garcia Rodriguez LA, Jones R. Morbidity associated with sleep disorders in primary care: a longitudinal cohort study. Prim Care Companion J Clin Psychiatry. 2007;9(5):338-345.

2. Gozmen S, Keskin S, Akil I. Enuresis nocturna and sleep quality. Pediatr Nephrol. 2008;23(8):12931296.

3. Austin PF, Bauer SB, Bower W, Chase J, Franco I, Hoebeke $P$, et al. The standardization of terminology of lower urinary tract function in children and adolescents: Update report from the standardization committee of the International Children's Continence Society. Neurourol Urodyn. 2016;35(4):471-481.

4. Ucer O, Gumus B. Quantifying subjective assess- 
ment of sleep quality, quality of life and depressed mood in children with enuresis. World $\mathrm{J}$ Urol. 2014;32(1):239-243.

5. Azevedo Soster L, Alves R, Fagundes SN, Koch VHK, Bruni O. Sleep disturbances associated with sleep enuresis: A questionnaire study. Eur J Paediatr Neurol. 2016;20(2):282-285.

6. Neveus T, Hetta J, Cnattingius S, Tuvemo T, Lackgren G, Olsson U, et al. Depth of sleep and sleep habits among enuretic and incontinent children. Acta Paediatr. 1999;88(7):748-752.

7. Ertan P, Yilmaz O, Caglayan M, Sogut A, Aslan S, Yuksel $\mathrm{H}$. Relationship of sleep quality and quality of life in children with monosymptomatic enuresis. Child Care Health Dev. 2009;35(4):469-474.

8. Esposito M, Gallai B, Parisi L, Roccella M, Marotta $\mathrm{R}$, Lavano SM, et al. Primary nocturnal enuresis as a risk factor for sleep disorders: an observational questionnaire-based multicenter study. Neuropsychiatr Dis Treat. 2013;9:437-443.

9. Byrd RS, Weitzman M, Lanphear NE, Auinger P. Bed-wetting in US children: epidemiology and related behavior problems. Pediatrics. 1996;98(3 Pt 1):414-419.

10. Kilicoglu AG, Mutlu C, Bahali MK, Adaletli H, Gunes $\mathrm{H}$, Duman HM, et al. Impact of enuresis nocturna on health-related quality of life in children and their mothers. J Pediatr Urol. 2014;10(6):1261-1266.

11. Meydan EA, Civilibal M, Elevli M, Duru NS, Civilibal $\mathrm{N}$. The quality of life of mothers of children with monosymptomatic enuresis nocturna. Int Urol Nephrol. 2012;44(3):655-659.

12. Tanriverdi $\mathrm{MH}$, Palanci Y, Yilmaz A, Penbegul N, Bez $Y$, Daggulli M. Effects of enuresis nocturna on parents of affected children: case-control study. Pediatr Int. 2014;56(2):254-257.

13. Doganer YC, Aydogan U, Ongel K, Sari O, Koc B, Saglam K. The Prevalence and Sociodemographic Risk Factors of Enuresis Nocturna among Elementary School-age Children. J Family Med Prim Care. 2015;4(1):39-44.

14. Bhatt GC. Enuresis and Sleep Disorders in Children. Indian Pediatr. 2015;52(11):995.

15. Abou-Khadra MK, Amin OR, Ahmed D. Association between sleep and behavioural problems among children with enuresis. J Paediatr Child Health. 2013;49(2):E160-166.

16. Hays RD, Stewart AL, Ware JE. Measuring functioning and well-being: the medical outcomes study approach. Durham, NC: Duke Univ. Press; 1992;23559.

17. Fera P, Lelis MA, Glashan Rde Q, Pereira SG, Brus- chini H. Desmopressin versus behavioral modifications as initial treatment of primary nocturnal enuresis. Urol Nurs. 2011;31(5):286-289.

18. Chua ME, Silangcruz JM, Chang SJ, Williams K, Saunders M, Lopes RI, et al. Desmopressin Withdrawal Strategy for Pediatric Enuresis: A Meta-analysis. Pediatrics. 2016;138(1).

19. Oguz U, Sarikaya S, Ozyuvali E, Senocak C, Halis $\mathrm{F}$, Ciftci M, et al. Family compliance with the use of alarm devices in the treatment of monosymptomatic nocturnal enuresis. Turk J Urol. 2014;40(1):52-55.

20. Ma Y, Liu X, Shen Y. Behavioral factors for predicting severity of enuresis and treatment responses in different compliance groups receiving behavioral therapy. Pak J Med Sci. 2017;33(4):953-958.

21. Arena S, Patricolo M. Primary nocturnal enuresis: Assessment and treatment at a single referral center. Pediatr Int. 2017;59(7):812-815.

22. Dhondt K, Van Herzeele C, Roels SP, Raes A, Groen LA, Hoebeke P, et al. Sleep fragmentation and periodic limb movements in children with monosymptomatic nocturnal enuresis and polyuria. Pediatr Nephrol. 2015;30(7):1157-1162.

23. Kushnir J, Cohen-Zrubavel V, Kushnir B. Night diapers use and sleep in children with enuresis. Sleep Med. 2013;14(10):1013-1016.

24. Oguz U, Aykac A, Demirelli E, Sancak EB, Resorlu B, Sarikaya S, et al. The Time of Spontaneous Resolution of Monosymptomatic Nocturnal Enuresis (MNE) Is Familial. Urol Int. 2015;94(4):459-463.

25. Soster LA, Alves RC, Fagundes SN, Lebl A, Garzon E, Koch VH, et al. Non-REM Sleep Instability in Children With Primary Monosymptomatic Sleep Enuresis. J Clin Sleep Med. 2017;13(10):1163-1170. 